\title{
Advance directives between respect for patient autonomy and paternalism
}

Trachsel, Manuel ; Mitchell, Christine ; Biller-Andorno, Nikola

DOI: https://doi.org/10.1007/978-94-007-7377-6_11

Posted at the Zurich Open Repository and Archive, University of Zurich ZORA URL: https://doi.org/10.5167/uzh-83552

Book Section

Originally published at:

Trachsel, Manuel; Mitchell, Christine; Biller-Andorno, Nikola (2013). Advance directives between respect for patient autonomy and paternalism. In: Lacker, Peter; Biller-Andorno, Nikola; Brauer, Susanne. Advance Directives. Dordrecht: Springer, 169-179.

DOI: https://doi.org/10.1007/978-94-007-7377-6_11 


\section{Metadata of the chapter that will be visualized online}

\begin{tabular}{lll}
\hline Chapter Title & \multicolumn{2}{l}{$\begin{array}{l}\text { Advance Directives Between Respect for Patient Autonomy and } \\
\text { Paternalism }\end{array}$} \\
\hline Copyright Year & 2014 & \\
\hline Copyright Holder & Springer Science+Business & Media Dordrecht \\
\hline Corresponding Author & Family Name & Trachsel \\
& Particle & \\
& Given Name & Manuel \\
& Suffix & \\
& Division & Institute of Biomedical Ethics \\
& Organization & University of Zurich \\
& Address & Pestalozzistrasse 24, CH-8032, \\
& Family Name & Mitchell Switzerland \\
\hline Author & Particle & \\
Given Name & Christine \\
Suffix & \\
Division & Division of Medical Ethics \\
& Organization & Harvard Medical School \\
& Address & 641 Huntington Avenue, Boston, MA, \\
& 02115, USA
\end{tabular}

Author

Family Name

Biller-Andorno

Particle

Given Name

Nikola

Suffix

Division

Institute of Biomedical Ethics

Organization

University of Zurich

Address

Pestalozzistrasse 24, CH-8032,

Zurich, Switzerland

Abstract

Advance directives frequently demand a certain degree of interpretation by the responsible physician or healthcare team. In implementing advance directives, healthcare professionals find themselves in an area of conflict between respect for autonomy, on the one hand, and paternalism on the other. Legal standards and ethical criteria for assessing the validity of advance directives are introduced and briefly discussed. The ethical criteria presented (accuracy of fit, plausibility/authenticity, lack of contradictions and coherent value system) can serve as important guides for appropriate and consistent interpretation of advance directives. In addition, the effect of advance directives on relationships is addressed from the perspective of the ethics of care. 


\subsection{Introduction}

There are two main types of advance directives. One type simply designates a 6 substitute decision-maker, sometimes called a healthcare agent, proxy or surrogate. 7 A more comprehensive advance directive (sometimes called a living will) specifies 8 particular principles or considerations intended to guide action with regard to 9 specific future healthcare decisions and possible medical conditions (Jaworska 10 2009).

At the time an advance directive is composed, the individual anticipates a future 12 situation in which s/he (1) will have lost decision-making capacity and (2) will be in 13 a condition that requires consent for or refusal of a medical intervention. Currently 14 competent individuals can thus make anticipatory decisions for possible future 15 healthcare situations.

The existence of an advance directive does not necessarily mean, however, that 17 it will be clear to the responsible physician in every case what the patient would 18 have decided. Problems with advance directives include, for instance, vagueness, 19 concerns about authenticity, applicability, the competence of the executor, implau- 20 sibility, internal contradictions, acceptability, and the suitability of the designated 21 surrogate decision-maker, as well as the question whether the anticipatory decisions 22 are what the patient would actually want now.

Notwithstanding these problems, advance directives are increasingly widely 24 recognized as a legal instrument: in many countries, including the US and most 25

\footnotetext{
M. Trachsel $(\bowtie) \cdot$ N. Biller-Andorno

Institute of Biomedical Ethics, University of Zurich, Pestalozzistrasse 24,

CH-8032 Zurich, Switzerland

e-mail: manuel.trachsel@gmail.com

C. Mitchell, RN, MS, MTS

Division of Medical Ethics, Harvard Medical School, 641 Huntington Avenue,

Boston, MA 02115, USA

e-mail: christine.mitchell@childrens.harvard.edu
} 
Western European states, the wishes expressed in an advance directive have to be respected regardless of the type and stage of disease (Vollmann 2012), unless the directive is legally invalid. However, patients have no claim right-i.e. they have no right to demand particular treatments, especially when these are expected to be futile (see e.g. Engelhardt 1989). Instead, patients have the right to consent to or refuse a particular recommended treatment, since every medical treatment represents an intrusion into a person's physical and mental integrity and therefore requires consent.

In many cases, a more or less broad range of interpretation is needed with regard to the meaning and implementation of an individual's healthcare decisions made in advance of their illness. This interpretative process is guided by a number of legal standards and ethical criteria, designed to avoid the traps of paternalism and neglect of autonomy.

\subsection{Between Respect for Autonomy and Paternalism}

In cases where decision-making incapacity is diagnosed, two situations can be broadly distinguished: either an advance directive is on hand or no written ${ }^{1}$ advance directive is on hand.

\subsubsection{Advance Directive on Hand}

Advance directives are designed to ensure that individual wishes expressed when the person was competent to do so are still respected in the event of decisionmaking incapacity. Ideally, the wishes formulated in the advance directive are in accordance with the patient's current best interests. However, the wishes expressed in the advance directive may sometimes be regarded as contrary to the incompetent patient's well-being.

According to Olick (2001), advance directives reflect "critical interests" with regard to personal dignity and well-being. Therefore, they have to be respected even if they conflict with current sensations of pleasure and pain. In this case, respect for autonomy - one of the four bioethical principles advocated by Beauchamp and Childress (2001) - is given more weight than the principle of beneficence. One

\footnotetext{
${ }^{1}$ Verbally expressed wishes are often taken into account in exploring the presumed wishes of the patient. However, they are clearly less authoritative than a properly executed written document. In the US, medical orders for life-sustaining treatment (MOLST) are treated like advance directives even though they are not initiated by the patient; they merely record the healthcare provider's conversation with the patient in the form of an order kept in the patient's medical record and applicable across various healthcare locations, such as hospitals, nursing homes, ambulances, hospices and the patient's home.
} 


\section{Author's Proof}

11 Advance Directives Between Respect for Patient Autonomy and Paternalism

example would be a patient's wish, expressed in an advance directive, not to receive 55 pain medication that could impair consciousness. Now, the patient, suffering from 56 end-stage cancer, is in a palliative situation in which only opioids could provide 57 significant pain relief. According to the advance directive, the physician is not 58 supposed to administer opioids, no matter how excruciating the patient's pain may be. 59

\subsubsection{No Advance Directive on Hand}

For patients who have not prepared an advance directive, treatment decisions are 61 made by surrogates such as family members (see e.g. Zellweger et al. 2008). Under 62 such circumstances, the principle of beneficence may sometimes be given greater 63 weight than respect for autonomy, as in the following case. An otherwise happy 64 elderly person with multiple chronic conditions and decision-making incapacity has 65 temporary kidney failure that could be reversed with dialysis. The patient does not 66 have an advance directive, but when still competent she stated repeatedly to family 67 members and medical care providers that she would not wish to be "dependent on 68 machines" to continue living. Nevertheless, in this case, the responsible 69 physician-having consulted the patient's relatives, who see this as a temporary 70 health crisis in an otherwise stable health situation with an apparently fair quality of 71 life-decides to treat the patient's kidney failure.

Tensions between respect for autonomy and beneficence frequently arise, 73 whether or not a patient has an advance directive. In attempting to resolve such 74 tensions, healthcare providers may err on the side of paternalism or on the side of 75 unwarranted respect for supposedly autonomous decisions which do not in fact 76 reflect competent choices.

\subsubsection{Paternalism}

Paternalism can be defined as "the interference of a state or an individual with 79 another person, against their will, and defended or motivated by a claim that the 80 person interfered with will be better off or protected from harm" (Dworkin 2010). 81 According to this definition, paternalism always involves a certain degree of 82 constraint on a person's freedom or autonomy for particular reasons. The following 83 two examples illustrate paternalistic behaviour:

1. Out of compassion, a forensic physician tells the parents of a victim of violence 85 that their daughter died instantly, whereas in fact she suffered a dreadful death. 86

2. The wife of an alcoholic hides her husband's liquor bottles because she is 87 worried about his health.

Paternalistic behaviour may be characterized as weak (soft) or strong. According 89 to weak paternalism, "a man can rightly be prevented from harming himself 90 


\section{Author's Proof}

(when other interests are not directly involved) only if his intended action is substantially nonvoluntary or can be presumed to be so in the absence of evidence to the contrary" (Feinberg 1971). Strong paternalism is embraced when a person is protected "against his will, from the harmful consequences even of his fully voluntary choices and undertakings" (Feinberg 1971).

An example of weak paternalism is the situation in which a patient specifies in his advance directive a desire to continue taking some sort of complementary medication; his physician, however, discovers that the medication causes significant harm to the patient, which she presumes the patient was not aware of. As she can no longer discuss this with the patient, who is now incompetent, she overrides the patient's advance directive, stopping the treatment for the patient's benefit.

An example of strong paternalism is a case where a patient whose valid advance directive clearly states that he refuses hospitalization for any medical reason is hospitalized overnight to receive intravenous hydration for life-threatening dehydration.

The motivation for potentially justifiable - weak or strong - paternalism is usually the desire to avoid harm (non-maleficence) and/or to benefit the person whose autonomy is overridden or compromised.

One could simply argue that, in sum, paternalistic behaviour probably produces more good than harm. But is this really true? According to Gerald Dworkin (2010), this largely depends on our understanding of the good. If the good simply comprises longer life, better health or relief from pain, paternalism might well be an effective strategy. However, for many people, the good also includes elements such as the right to make self-guided decisions. While paternalism can be considered an acceptable moral stance when autonomy is absent or at least in doubt, overriding an individual's explicit, autonomous choice for the sake of promoting his or her well-being is difficult to justify morally.

\subsubsection{Respect for Autonomy}

Autonomy or self-determination is a person's ability to make his or her own selfguided decisions. The principle of respect for autonomy obligates healthcare professionals to honour competent patients' informed, voluntary decisions.

According to Ronald Dworkin (1993), a person with the capacity for autonomy needs (1) the ability to espouse a "genuine preference or character or conviction or a sense of self", which could be called the ability to value, and (2) the ability to act out of one's sense of conviction, which Jaworska (2009) calls "the ability to enact one's values in the complex circumstances of the real world". These crucial abilities are missing in many disorders, such as severe dementia or loss of consciousness.

If it is possible to apply a specific advance directive directly to a given situation, a conflict between respect for autonomy and paternalism may not occur. In this case, the expressed wishes can be transformed into action without restriction. 


\section{Author's Proof}

11 Advance Directives Between Respect for Patient Autonomy and Paternalism

However, the conflict becomes relevant if an advance directive is formulated 131 vaguely or cannot be directly applied to the present medical situation. In this 132 more difficult case, the advance directive can only serve as a decision aid or a 133 source for inferring the patient's presumed wishes. For example, if an advance 134 directive contains a detailed statement of treatment preferences for end-stage 135 cancer, this statement is not necessarily useful if the patient suffers not from cancer 136 but from end-stage liver cirrhosis with hepatic encephalopathy and loss of con- 137 sciousness. This example refers to the accuracy of fit that is part of the validity of 138 advance directives (see Sect. 11.3). 139

But even if choices are clearly expressed and obviously apply to a specific 140 situation, the range of choices that need to be respected is not unlimited: for 141 example, certain preferences would impose an undue risk or burden on others, 142 costly but futile interventions would place an unjustifiable burden on a limited 143 public healthcare budget, and refusal of basic hygiene might be intolerable for those 144 who care for the patient. The exact scope of what can be claimed or refused is 145 controversial. Disagreements over what wishes need to be respected and what one 146 person can legitimately ask of another are illustrated by the case of active 147 euthanasia.

\subsection{Legal Standards and Ethical Criteria for Assessing the Validity of Advance Directives}

\subsubsection{Legal Standards}

In most countries, legal standards for a valid advance directive require a written 152 form that is personally signed by a person who is of age (legal majority), has 153 decision-making capacity, is informed about the decision to be taken (including 154 alternatives to the chosen action), and is able to make and communicate a free 155 (uncoerced) choice.

At the time of composing an advance directive, a person is required to have 157 decision-making capacity. The following criteria are typically used for medical 158 decision-making capacity: (1) ability to understand the relevant information, 159 (2) ability to appreciate the medical consequences of the situation, (3) ability to 160 reason about treatment choices, and (4) ability to communicate a choice 161 (Appelbaum and Grisso 1988). Criteria may differ slightly from country to country, 162 but the basic concept is the same (see e.g. Swiss Academy of Medical Sciences 163 2005). A variety of instruments aid the assessment of decision-making capacity 164 (Sessums et al. 2011).

Decision-making incapacity is caused by a broad range of clinical conditions, 166 such as loss of consciousness due to severe somatic illness, dementia (e.g. 167 Alzheimer's disease or Lewy body disease), brain injury and psychiatric diseases 168 (e.g. schizophrenia or severe depression). 


\section{Author's Proof}

It is especially difficult to assess retrospectively whether a patient had decisionmaking capacity at the time he or she composed an advance directive. Frequently, a patient diagnosed as incompetent to make a particular healthcare decision has an advance directive that was written many years ago. If, for instance, a patient suffers from slow progressive dementia, it can be difficult to establish whether the person was still competent 5 years ago when he or she wrote the advance directive. The ethical criteria presented below can be used to test the moral appropriateness of heeding the contents of an advance directive. In addition, it may be helpful to interview relatives, friends, physicians and other care professionals who have been in contact with the person over a longer period.

Free choice means that a person composing an advance directive has to be able to make an autonomous decision and to communicate the choice without feeling threatened, under duress or external pressure. Ideally, the living will originates from a person's idiosyncratic substrate of wishes and values. According to Beauchamp and Childress (2001), three conditions constitute an autonomous decision: (1) the act was carried out intentionally, (2) the act was carried out with an understanding of the important facts and circumstances and (3) the act was carried out without external "controlling influences".

If these legal standards are not met, the advance directive cannot be used to justify medical decisions. If the legal standards are met, an analysis based on ethical criteria can follow.

\subsubsection{Ethical Criteria}

When an advance directive is formulated vaguely or cannot be directly applied to the present medical situation, criteria are needed to judge its ethical validity, helping to prevent unwarranted paternalism or undue respect for autonomy in cases where there was no competent choice. Four main characteristics have been proposed as ethical criteria for assessing the validity of advance directives (see also Trachsel et al. forthcoming):

1. accuracy of fit

2. plausibility/authenticity

3. lack of contradictions

4. coherent value system

Accuracy of fit means that the clinical situation in question corresponds to the situation envisaged in the advance directive. This does not necessarily imply that advance directives have to be overly specific, as it may be difficult or impossible for the patient to fully anticipate the details of their diagnoses and prognoses, and to make an informed choice based on an appreciation of the options available. However, it is certainly helpful for the patient, family members and the health professionals concerned if the patient's preferences and values are clearly stated, as 


\section{Author's Proof}

11 Advance Directives Between Respect for Patient Autonomy and Paternalism

well as any particular wishes about interventions such as blood transfusions or 209 mechanical life support in the form of ventilators, artificial hearts, etc.

An advance directive is plausible and authentic when it is in accordance with 211 one's distinctive wishes, personality, character and lifestyle. For relatives and 212 physicians who know the patient, an advance directive will be easiest to accept as 213 representative of the patient's wishes when the content is consonant with his or her 214 personal traits.

The concept of authenticity has been extensively debated (e.g. Golomb 1995; 216 Wood et al. 2008). According to a widely shared position (Frankfurt 1988; Glannon 217 2008), persons are authentic if they can identify with their mental states. For 218 example, wishes expressed with regard to pain medication are authentic if they 219 are formulated by a person who has suffered from chronic pain (mental state) for 220 years, and if the person is able to attest through her or his higher-order reflective 221 capacity that this chronic pain is relevant to the wishes specified in the advance 222 directive.

However, authenticity is not a legal requirement for the validity of advance 224 directives, and it is contentious as an ethical criterion (Brauer 2008). Legally, a 225 person is free to refuse a certain treatment regardless of his or her reasons and even 226 in the absence of particular reasons. Accordingly, Olick (2001) states that an 227 advance directive is not required to be an authentic expression of its author. The 228 requirement of authenticity would open the floodgates to paternalistic actions, as it 229 would be quite easy to evaluate an advance directive as non-authentic and 230 non-autonomous. Instead, it is sufficient to see an advance directive as an "inten- 231 tional plan to assert control over one's dying process" (Olick 2001).

It seems self-evident that an advance directive should not contain internal 233 contradictions or contradictory instructions with regard to one and the same 234 medical situation. For instance, a patient's living will cannot be honoured when 235 one part of the advance directive refuses withdrawal of treatment in every imagin- 236 able situation and requests that everything possible be done to obtain a lung 237 transplant, while another part of the same advance directive requests withdrawal 238 of treatment in end-stage cystic fibrosis.

The ethical validity of an advance directive is more obvious when the wishes 240 expressed are evidently based on a coherent value system. This can be defined as a 241 set of values that are interconnected in a logical and hierarchical manner and that 242 guide a person's preferences, decisions and actions. The value system need not be 243 highly complex and abstract, nor does the absence of an identifiable coherent value 244 system render an advance directive invalid. In fact, it is controversial whether and 245 how ethical values should be communicated to healthcare professionals and 246 relatives via an advance directive at all (Brauer 2008).

The ethical criteria described above can provide important guidance in assessing 248 the validity of advance directives that are, for instance, formulated vaguely or 249 cannot be directly applied to the clinical situation (see also Trachsel 250 et al. forthcoming). However, it is important to discuss the precise role of these 251 criteria in the assessment. Some, such as accuracy of fit and lack of contradiction, 252 are fairly uncontroversial as a matter of principle but may be applied more or 253 
less strictly. Others, such as authenticity and a coherent value system, remain controversial as regards both interpretation and appropriateness. Even so, they capture important aspects of the debate on advance directives and can help to articulate the reasons for moral disagreement.

The criteria discussed in this section focus on the choices expressed by a rational individual moral agent. However, the situations advance directives aim to anticipate are likely to be characterized to a great extent by dependence on others. It is thus of interest to explore what a relational perspective can add to the discussion on advance directives.

\subsection{Advance Directives and Relationships: The Ethics of Care Perspective}

The fundamental conflict between respect for autonomy and paternalism is part of every social relationship. Alongside other ethical approaches, the ethics of care (Held 2005) provides an important theoretical perspective on this conflict.

The ethics of care is a form of relational ethics in the sense that "its central focus is on the compelling moral salience of attending to and meeting the needs of the particular others for whom we take responsibility" (Held 2005). The ethics of care respects the fact that persons depend on others for most of their lives. The ethics of care "addresses rather than neglects moral issues arising in relations among the unequal and dependent, relations that are often emotion-laden and involuntary" (Held 2005). The family context is prototypical for such relations.

Degrees of dependence may vary over the life course; for instance, children or persons in situations of illness or after accidents will need a lot of care. But even healthy adults are likely not to be completely self-sufficient, but need others even for their everyday professional and private activities. Later in life, many people need care every day, and some individuals with disabilities may be dependent on care throughout their lives.

Most people composing an advance directive do so with a view to a future situation of involuntary dependence in which they need the care of others. Focusing on individual preferences and trying to extend individual autonomy may not do justice to the challenges posed by this new state of significant need and dependence.

On the other hand, advance directives are not necessarily antithetical to a care perspective. The ethics of care does not postulate that there is no room for private decisions that may also go against the expectations or wishes of close persons. Advance directives can specify the relational network in which the individual is situated and highlight trustful relationships. Also, advance directives need not be a vote of no confidence in the treating physicians or caring relatives; they may even serve as an "icebreaker", making it easier for healthcare professionals and relatives to communicate about the patient's preferences and interests. Not surprisingly, a randomized controlled study found that advance care planning including the 


\section{Author's Proof}

11 Advance Directives Between Respect for Patient Autonomy and Paternalism

formulation of an advance directive "improves end of life care and patient and 294 family satisfaction and reduces stress, anxiety, and depression in surviving 295 relatives" (Detering et al. 2010).

Furthermore, the ethics of care values sympathy, antipathy, anger, respon- 297 siveness or other feelings as important moral emotions that should guide behaviour 298 no less than rational arguments. This puts a new complexion on the conflict between 299 respect for autonomy and paternalism. Even if an advance directive is not fully 300 consistent and rational, this does not mean that it is completely irrelevant and that 301 the only option is to override it in a paternalistic manner. Instead, it is advisable to 302 place more reliance on the emotions expressed in the document, which can provide 303 an important basis for discussing the implementation of an advance directive.

\subsection{Consistency in the Implementation of Advance Directives}

Ethical criteria for assessing validity need to be calibrated in such a way as to strike 307 a balance between paternalism and a form of consumerism that would let patients 308 have their way even if their advance directive is not an expression of a competent 309 choice. Even though some of the requirements (e.g. for a coherent value system) 310 may be controversial, measuring individual advance directives against these ethical 311 criteria can help to promote consistent implementation among physicians and 312 healthcare teams. Beyond individual judgements, the ethical criteria also provide 313 a framework for discussing consistent implementation of advance directives within 314 medical communities (e.g. groups of providers or medical subdisciplines). 315

The requirement for consistency is fairly straightforward: if two similar patients 316 with similar health problems compose similar advance directives, the patients 317 should be treated similarly. If the two patients, their health problems or their 318 advance directives differ in essential respects, it is perhaps not appropriate to 319 treat the two patients similarly. Yet this claim raises a lot of questions. Should 320 patients with decision-making incapacity who have the same disease (e.g. end-stage 321 brain cancer) and a very similar advance directive be treated similarly, even if 322 one patient is 30 and the other 90 years old? Perhaps both have stated in their 323 advance directive that they do not wish to receive further surgical treatment for their 324 cancer once they become incapable of decision-making. Intuitively, one may be 325 more inclined to accept this living will if the patient is 90 because of the whole life 326 span we could imagine ahead of the 30-year-old patient. Yet this would constitute an 327 age bias that is not part of the advance directive concept. An advance directive is 328 valid regardless of the patient's age. For instance, even a child of 10 years can have 329 decision-making capacity with regard to some vitally important decisions. 330

There may be other sources of potential bias: physicians may be more inclined to 331 implement an advance directive if they agree with the wishes expressed by the patient. 332 Thresholds for the validity of an advance directive might be raised when physicians 333 


\section{Author's Proof}

completely disagree with the content of an advance directive, particularly with regard to morally highly charged issues such as assisted suicide. Economic factors might also influence the acceptance of an advance directive. Relatives might, for instance, not want to let go of their loved one and argue for a very strict interpretation of standards; conversely, they might be worried about the costs accumulating for the care of their relative, whose quality of life they consider to be very poor. The requirement of consistency calls for a given advance directive to be interpreted in the same way regardless of biasing factors.

\subsection{Conclusions}

In cases where decision-making incapacity is diagnosed, the existence of an advance directive does not necessarily mean that it will be clear to the responsible physician in every case what the patient would have decided. Problems with advance directives include vagueness, the question of authenticity, applicability, the competence of the executor, implausibility, internal contradictions, acceptability, or the question whether the anticipatory decisions are what the patient would actually want now.

Because advance directives are not always clearly formulated, a certain degree of interpretation is demanded of the responsible physician. In interpreting advance directives, healthcare professionals find themselves in an area of conflict between respect for autonomy, on the one hand, and paternalism on the other.

Besides legal requirements, it is important to apply ethical criteria-including accuracy of fit, plausibility/authenticity, lack of contradictions and a coherent value system - for assessing the validity of advance directives, although there is certainly room for discussion as to the specific requirements which these criteria should entail.

The fundamental conflict between respect for autonomy and paternalism is part of every social relationship. Alongside other ethical approaches, the ethics of care (Held 2005, 2006) provides an important theoretical perspective on this conflict. Advance directives are composed for a future situation of involuntary dependence, in which someone needs the care of others. Advance directives are not a vote of no confidence and could even ease the burden on close relationships, serving as critical icebreakers for communication between patients, relatives and healthcare professionals regarding the care patients receive when they are no longer able to speak for themselves.

\section{References}

Appelbaum, Paul S., and Thomas Grisso. 1988. Assessing patients' capacities to consent to treatment. The New England Journal of Medicine 319(25): 1635-1638.

Beauchamp, Tom L., and James F. Childress. 2001. Principles of biomedical ethics, 5th ed. New York: Oxford University Press. 


\section{Author's Proof}

11 Advance Directives Between Respect for Patient Autonomy and Paternalism

Brauer, Susanne. 2008. Die Autonomiekonzeption in Patientenverfügungen - Die Rolle von 371 Persönlichkeit und sozialen Beziehungen. Ethik in der Medizin 20(3): 230-239. 372

Detering, Karen M., Andrew D. Hancock, Michael C. Reade, and William Silvester. 2010. The 373 impact of advance care planning on end of life care in elderly patients: Randomised controlled 374 trial. BMJ 340: c1345. $\quad 375$

Dworkin, Ronald. 1993. Life's dominion: An argument about abortion, euthanasia, and individual 376 freedom, 1st ed. New York: Knopf. 377

Dworkin, Gerald. 2010. Paternalism. In The Stanford encyclopedia of philosophy (Summer 2010378 edition), ed. Edward N. Talta. http://plato.stanford.edu/entries/paternalism/ 379

Engelhardt Jr., H. Tristram. 1989. Advance directives and the right to be left alone. In Advance 380 directives in medicine, ed. Chris Hackler, Ray Moseley, and Dorothy E. Vawter, 141-154. 381 New York: Praeger.

Feinberg, Joel. 1971. Legal paternalism. Canadian Journal of Philosophy 1(1): 105-124. 383

Frankfurt, Harry G. 1988. Identification and wholeheartedness. In The importance of what we care 384 about, ed. Harry G. Frankfurt. New York: Cambridge University Press. 385

Glannon, Walter. 2008. Psychopharmacological enhancement. Neuroethics 1(1): 45-54. 386

Golomb, Jacob. 1995. In search of authenticity: From Kierkegaard to Camus. London: Routledge. 387

Grisso, Tom, and Paul S. Appelbaum. 1998. Assessing competence to consent to treatment: 388 A guide for physicians and other health professionals. New York: Oxford University Press. 389

Held, Virginia. 2005. Ethics of care. In The Oxford handbook of ethical theory, ed. David Copp. 390 New York: Oxford University Press. 391

Held, Virginia. 2006. The ethics of care: Personal, political, global. Oxford: Oxford University 392 Press. 393

Jaworska, Agnieszka. 2009. Advance directives and substitute decision-making. In The Stanford 394 encyclopedia of philosophy (Summer 2010 edition), ed. Edward N. Talta. http://plato.stanford. 395 edu/entries/advance-directives/ 396

Olick, Robert S. 2001. Taking advance directives seriously: Prospective autonomy and decisions 397 near the end of life. Washington, DC: Georgetown University Press. 398

Sessums, Laura L., Hanna Zembrzuska, and Jeffrey L. Jackson. 2011. Does this patient have 399 medical decision-making capacity? JAMA: The Journal of the American Medical Association 400 306(4): 420-427. 401

Swiss Academy of Medical Sciences. 2005. Recht der Patientinnen und Patienten auf 402 Selbstbestimmung. Medizinisch-ethische Grundsätze. Basel: SAMW. 403

Trachsel, Manuel, Christine Mitchell, and Nikola Biller-Andorno. Forthcoming. Decision-making 404 incapacity at the end of life: Conceptual and ethical challenges. Bioethica Forum. 405

Vollmann, Jochen. 2012. Patientenverfügungen von Menschen mit psychischen Störungen. 406 Gültigkeit, Reichweite, Wirksamkeitsvoraussetzung und klinische Umsetzung. [Advance 407 directives in patients with mental disorders. Scope, prerequisites for validity, and clinical 408 implementation]. Der Nervenarzt 83(1): 25-30. 409

Wood, Alex M., P. Alex Linley, John Maltby, Michael Baliousis, and Stephen Joseph. 2008. The 410 authentic personality: A theoretical and empirical conceptualization and the development of 411 the Authenticity Scale. Journal of Counseling Psychology 55(3): 385-399. 412

Zellweger, Caroline, Susanne Brauer, Christopher Geth, and Nikola Biller-Andorno. 2008. 413 Advance directives as an expression of individualistic autonomy? The role of relatives in 414 advance directive forms. Ethik in der Medizin 20(3): 201-212. 


\section{Author's Proof}

\section{Author Queries}

Chapter No.: $11 \quad 0002030390$

\begin{tabular}{|l|l|l|}
\hline Queries & Details Required & Author's response \\
\hline AU1 & $\begin{array}{l}\text { Please confirm the corresponding } \\
\text { author. }\end{array}$ & \\
\hline AU2 & $\begin{array}{l}\text { Please provide citation for Grisso and } \\
\text { Appelbaum (1998). }\end{array}$ & \\
\hline AU3 & Please update Trachsel (forthcoming). & \\
\hline
\end{tabular}

